amenable to its workings. Parasitism, while not so common, warrants study for the reason no illustration of the relation between structure and function is more striking. Degeneracy comes in this same connection.

Insects, birds, and many of our native wild mammals lend themselves to many of the above lines of work. Find out why the woodpecker's outer toe is permanently reversed, why the tail feathers are stiff and blunt, why the tongue is barbed and is so strongly protrusible, why the head is rather heavy, why the bill is strong, and the student has then touched a number of facts bearing upon nesting habits, food, and feeding habits. These may be simple, but they are fundamental to an understanding of the bird. The external physiology is then very largely disposed of and internal physiology partially so. I am aware that these things seem largely ecological in character, but they are first physiological. Ecology is, in the main, simpiy external physiology, this latter having oftentimes an internal morphological response.

Even in the microscopic work let the physiological work be kept in the foreground. The student should be encouraged to see the animal do things as well as to see the parts of the animal. A vactiole in itself is nothing; its function is the important thing. An insistance, then, on a study of function, when morphology is being considered will result in better work and constitutes the third proposed remedy.

\title{
A NEW GAS GENERATOR.
}

\section{By Fredus N. Peters, Central High School, Kansas City, Mo.}

Everyone who has occasion to use a Kipp generator knows of the difficulties and annoyances which are experienced whenever it is allowed to stand for some time. The acid in contact with the iron sulphide, or whatever the material may be, becomes spent and that in the reservoir above, which is unused, must be thrown out with the other. The apparatus is seldom ready when you want it unless it has been recently charged.

Many attempts have been made to obviate these difficulties; and various modifications of the Kipp have been proposed, but most 
of them are open to some objections. At the holiday meeting in December of the State Association of Science Teachers of Missouri, the model of a new form designed by Mr. Farl C. Hallar, of the department of Chenistry of Central High School, Kansas City, presented a new model of gas generator which seems to be satisfactory in every way. From the accompanying figure its construction will be readily understood. $B$ is a bottle of about one liter capacity, having a wide mouth; $A$ is another

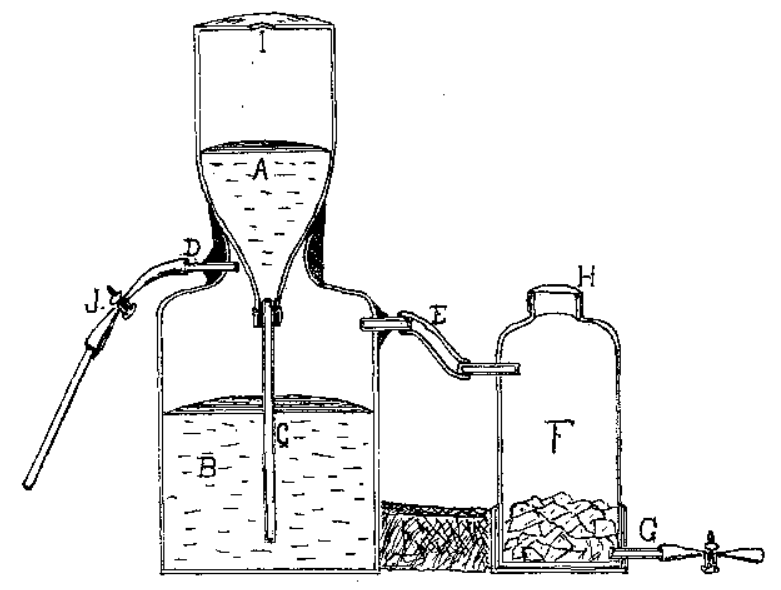

bottle of about $500 \mathrm{cc}$. capacity with tapering neck which fits into B. A hole is bored through the bottom of this at I by means of a file moistened with turpentine; a tube $C$ extends nearly to the bottom of $\mathrm{B}$. F is a bottle for holding the ferrous sulphide, marble, zinc, carbide, etc., and is connected with $B$ by means of a rather large (about $3 / 8$ in.) rubber tubing, upon which a screw clamp, not shown in figure, is placed to regulate the flow of the liquid, which differs for different gases. F rests loosely in another larger bottle cut off short, which is fastened by wax to B quite securely. $\mathrm{H}$ is a ground glass stopper, which, if not gas tight, is readily made so from a few drops of wax from a candle. This is easily removed when necessary for recharging, which need not be often. For the generation of acetylene for class purposes a pint Mason glass jar is used for $F$. To use the apparatus the acid is poured into $A$ at $I$, from which it runs down into $B$, and from there into $F$. The tube $E$ must be large enough to permit the passage of the acid and at the same time of the gas generated in $\mathrm{F}$. For generating hydrogen sulphide small quantities of acis 
are all that is necessary, while for carbon dioxide more is needed. This quantity is readily controlled by the screw clamp at $E$. When the material in $F$ is becoming covered with a spent acid it may readily be drawn off from $G$ without interfering in any way with the working of the apparatus. If it is desired to prepare hydrogen instead of hydrogen sulphide, all one has to do is to disconnect at $\mathrm{E}$, substitute for $\mathrm{F}$ a similar bottle with zinc, and proceed; likewise for carbon dioxide a bottle of marble.

Another advantage the apparatus has is that if the supply of material in F runs low while it is desired to continue the use of the gas an amount of acid sufficient to generate gas enough to nearly fill the reservoir $B$ may be allowed to pass over into $F$. and while the student or instructor is drawing this off through I the clamp at $\mathrm{E}$ may be closed and the bottle $\mathrm{F}$ recharged.

Thus far the apparatus is only in the "home-made" condition, but it will probably be put upon the market for the coming season by one of the large supply houses of the country. It has been tried for some months in the laboratory and lecture room at Central High School at Kansas City, and many changes made in it since it was first tested. The result is that it seems to be now in a most satisfactory condition. Mr. Hallar has also proposed to make one other change, not shown in the figure, which, how-ever, will render it a little more complicated. At present it is so simple that anyone can make the apparatus in a few hours, and feel sure when it is done that he will have a generator which will meet all his requirements.

Common sealing wax may be used to connect the two bottles. $B$ and $F$, and to seal the tubes $E$ and $D$ to $B$, but it is not altogether satisfactory, as it gradually breaks loose. A more satisfactory cement may be prepared by me!ting together the following: $\mathrm{x} / \mathrm{d} \mathrm{lb}$. rosin, $\mathrm{y} / \mathrm{lb}$. beeswax, $1 / 4 \mathrm{lb}$ red ochre or Venetian red, I teaspoonful plaster of Paris.

If put upon the market it is expected there will be four separate bottles for F, suited to the preparation of hydrogen sulphide, carbon dioxide, hydrogen, and acetylene, but these are merely for greater convenience and not necessary. 